10 years ESJ

Special edition

\title{
The Project Manager "Language" in a Crisis Scenario
}

\author{
Daniele Di Lorenzo (MBA, PMP, CSPO) \\ Freelance, Italy
}

\section{Doi: $10.19044 /$ esj.2021.v17n11p3}

Submitted: 18 September 2020

Accepted: 22 January 2021

Published: 02 April 2021
Copyright 2021 Author(s)

Under Creative Commons BY-NC-ND

4.0 OPEN ACCESS

Cite As:

Di Lorenzo D. (2021). The Project Manager "Language" in a Crisis Scenario. European Scientific Journal, ESJ, 17(11), 3. https://doi.org/10.19044/esj.2021.v17n11p3

\begin{abstract}
A pandemic scenario may add time and space limits to the relationships that exist between people and businesses. It is reasonable to assume that multiple projects are conditioned by those limitations. As a result, they should follow the same constraints. Two fundamental views that project managers should focus on during the management of projects are the technical-operative modalities they use to advance the activities and their mindset to manage their dynamics. The union of these two dimensions can be regarded as the "language" of project managers. This paper focuses on analyzing the impacts of pandemics on these dimensions and the ways through which these conditions could change the "language" to properly react to this kind of crisis. As argued here, the variables of "triad" (Reaction-ExecutionResults) combined with an appropriate mindset and the usage of a micro-goal approach could be an effective reply to a pandemic.
\end{abstract}

Keywords: Project Manager, Mindset, Crises, Triad, Reaction

\section{Introduction}

Project management is "the application of knowledge, skills, tools, and techniques to project activities to meet the project requirements. Project management is accomplished through the appropriate application and integration of the project management processes identified for the project. Project management enables organizations to execute projects effectively and efficiently." (Project Management Institute, 2017) 
However, managing projects means to apply the principles and good practices well described by international standards/frameworks. Some of these standards include "A Guide to the Project Management Body of Knowledge PMBOK Guide" from the Project Management Institute (PMI) (Project Management Institute, 2017); "Projects in Controlled Environments Prince2" from Axelos, "Individual Competence Baseline - ICB4" from the International Project Management Association, Scrum; and "ISO 21500:2012" from the International Standardization Organization (2012). This allows managers to guarantee the aid from the different souls of the project. This study focuses on the disciplines of project management and the role of the project managers that work daily by monitoring several areas of knowledge that allow them to understand the status of the project in a specific moment. Following a model of the PMBOK ${ }^{\circledR}$ structure (Project Management Institute, 2017), some areas of knowledge includes integration management, time management, resource management, communication management, stakeholder management, etc. The reference is, by way of example, time management techniques such as parallelization of activities or identification of critical paths, progress working reports and processed numbers in order to meet the preset deadlines, verification of procurement contracts and the evaluation of bindings elements inside, risk analysis and identification of the related reaction plans, tools such as product backlog or kanban board in order to visualize the tasks status, and story mapping to plan the product release to the customers. Two of the most common project lifecycles that organizations use to deliver projects are "Adaptive" and "Predictive". "Predictive" approaches, also known as Waterfall methodology, rely on an early phase analysis and a detailed breakup of features and tasks for the entire development process of the product, service or result. "Adaptative" approaches, also known as Agile framework which is based on the Agile Manifesto ${ }^{1}$, focuses on quickly adapting to changing scope and project reality. This paper assumes that skilled project managers with their structured training, international certifications, and work experience may steer projects using the proper knowledge and by adhering to the specific scenario at the specific time to reach project fulfilment and success. The knowledge of project managers is usually considered (implicitly or explicitly) as the harmonized union of two fundamental dimensions, which is the technical-operative modalities that were chosen in order to advance the activities and their mindset to manage the dynamics of projects. This union may be read as the "language" of project managers, which is seen as their modus operandi in managing that project. This outlook is true for both a normal scenario and a pandemic situation. Therefore, this paper focuses on analyzing the impact of a pandemic on these

${ }^{1}$ http://agilemanifesto.org 
two dimensions and how the "language" could change at application level of project management to properly react to that kind of crisis.

\section{Sources and Method}

The method used to identify the sources by which this study will develop the content consists of three search directions, which will lead to identifying the appropriate sources. On one hand, this will provide a better understanding of the current state in the field of project management. On the other hand, this will integrate the various contributions present in the literature so as to provide the answer to the impacts of a pandemic. The first direction involves the major international project management associations that make their methods and methodologies available. This includes publications relating to personal development and corporate maturity. This means that it will be explicit based on the current "state of art" on project management disciplines. The second direction uses the web search engines (at least two) which identifies related topics and specific publications through the use of keywords such as "crisis", "goal", "management", "pandemic", "chaos", "react", and "emergency". The goal is to identify interest and specific contributions on the topic of crisis management that can support the thesis detailed in the study. The last direction is in line with international entities, which is created to standardize and provide answers to different scenarios such as the pandemic situation. The main entities are the International Organization for Standardization (2012) and the World Health Organization (2009).

\section{Project Managers Role}

The "language" used by project managers is indissolubly composed of two interconnected dimensions that combine to give life to the specific expressive modality of the discipline in the operative phases:

1. The one which emerges from the effect of their decision making, which has significant impacts on the technical-operative modality. Each deliverable project released by a project team involves the dynamics of the project and the real possibility that what has been established will be executed and delivered within the stated deadlines.

2. The one that features the mindset of the management approach, which makes it possible to identify a verbal, non-verbal, and behavioral language that characterizes the persons.

The main international project management associations such as the Project Management Institute ${ }^{2}$ and Axelos $^{3}$ are used to propose methodologies

${ }^{2}$ https://www.pmi.org

${ }^{3}$ https://www.axelos.com 
based on processes in order to technically manage projects as well as the growth paths of project managers' competences (Project Management Institute, 2017; Franklin \& Tuttle, 2008). In the adaptative lifecycle approach, these two dimensions are mixed and embedded into a specific framework. The Scrum Guide describes the basic tools, events, and artifacts. At the same level, it describes the change of mindset for each of the identified rule to implement an Agile culture in the company (Schwaber, 2017).

A project, by definition, has a beginning and an end. Moreover, it is equipped with clear and agreed requirements, and the achievements mark the end of the project itself (Project Management Institute, 2017). The aims of a project can be multiple, but well identified. The goal is always to finish activities on time, within budget, and based on quality as agreed with the customer.

In a standard scenario, project managers use their technical background to reach their goals. While intending to use a predictive approach such as $\mathrm{PMBOK}^{\circledR}$ structure, the sequence of plausible activities could be the elicitation of additional customer requirements in order to provide completeness to the product or service. As a result, the project has to identify all activities and risks, develop a realistic plan for the execution, never lose sight of the balance of need resources, plan communication especially towards stakeholders, monitor the budget and the fulfilment of requirements, check the change to project scope, and verify the conditions for closing the project. Moving to an adaptive approach such as Scrum, the sequence of plausible activities could be the identification of the basic requirements (usually named "User Stories"), which is placed in a product backlog with a priority. Thereafter, choose the activities to carry out during the following weeks (called "Iteration"), check the change of requirements and add them to the next iteration. Finally, verify the impediments to the team and remove them, verify the results with the customer (identified as "value" released to him), and evaluate together how to proceed. Project managers are engaged day-by-day in the integration of all the elements mentioned above in order to preside over the status of the project. In addition to these aspects that are endowed with a "quantitative" nature, there are others with a "qualitative" nature that is crucial. The team growth, improvement of relations with stakeholders, and the positive perception of the company are examples of views that flow into the dimension of the mindset. The decision-making processes result in a project managers' "management language" that is adopted. Project managers may use all tools or techniques available in literature as well as those that are suitable for the scenario. Furthermore, it is important to satisfy the deadline and milestone agreed with the customer and stakeholders. 
The word "pandemic" comes from the Greek "pan-demos" which means "all the people"4. This means that "all the people" are affected by a pandemic event. Therefore, "all the people" are impacted by medical-health constraints and the related interaction modality is usually temporarily modified. By transposing what has been said into the world of projects, new mandatory requirements are being added and the projects in their entirety must meet. The presence of a pandemic from a management point of view is synonymous to project management within the perimeter of the crisis caused by the pandemic. Thus, the word "crisis" is implicitly referred to as the "pandemic" scenario that generated the crisis itself. Lagadec Patrick (1993) defines a crisis as an incident that upsets normal conditions, creating a disturbance that cannot be brought back to normal using existing or specialized emergency functions. This definition involves new and typically unanticipated decisions that have to be made. Therefore, new requirements must be added to the project scopes.

During the pandemic period, it is reasonable to think of constraints such as a limited possibility of movement of resources, limited range of supply, the way of acting only in certain time windows and only under suitable medical and health conditions, introduction of medical-bureaucratic procedures to guarantee the safety of the population, uncertainty of the duration of the pandemic, and different constraints in different nations. Based on the decisions of the government about the lockdown, Akbar Azwir (2020) states that "people's movement is limited, stores and business activity are closed, and only essentials services are exempted. This brings a significant impact on projects, and as a project manager, you need to build a strong project resilience". The "Pandemic influenza preparedness and response" document (World Health Organization, 2009) and the specific "National plan for preparedness and response to an influenza pandemic" documents (National Centre for the Prevention and Control of Disease, 2020) issued by the World Health Organization ${ }^{5}$ are two significant examples of how guidelines have significant impact on the life and habits of a community. Subsequently, the importance of transparency and coherence in communicating information is clearly highlighted. KPMG Australia ${ }^{6}$ offers lessons learned for an effective response to a pandemic by identifying the remote leadership and the disciplined agility, which are two of four main implications for project managers (KPMG Australia, 2020).

Mallak, Kurstedt, Harold, and Patzak offer a brief list of emergency management planning tools and skills such as risk analysis, contingency plans, logic charts, and tabletop exercises in order to help project managers in a crisis

\footnotetext{
${ }^{4}$ http://www.treccani.it/vocabolario/pandemia/

${ }^{5}$ https://www.who.int

${ }^{6} \mathrm{https} / / / \mathrm{home.kpmg/au/en/home.html}$
} 
scenario (Mallak, Kurstedt \& Patzak, 1997). Besides the tools, the authors propose recommendations for project managers that highlight the desire to trigger correct and fast reaction methods. This is supported by appropriate techniques such as risk analysis in order to reach the suitable results.

Therefore, the dimensions identified above are inevitably impacted by the crisis. Considering project managers' technical-operative modality in conducting a project, the "variables" to be governed with greater incisiveness are speed of reaction, decision-making, fast execution, and certainty of results within the specific time available. Hence, the characterizations of the highly dependent variables (Reaction-Execution-Results) need to be analyzed. This study will refer to them as the "triad". The velocity of Reaction is an important element in project management. Assuming a pandemic binds people, bureaucratic approvals, handling of goods and additional activities such as mandatory means of medical protection, health certificates, sanitization or sterilization of environments signifies that the ability to react to the evolution of the pandemic scenario must be amplified. When the technical-sanitary and bureaucratic-legislative conditions are suitable, it is necessary to make the decision and, consequently, take actions. This implies that before these conditions occur, the reactive steps must be analyzed in terms of potential scenarios and the related action/reaction plans should be drawn up. The Execution, at this point, is the realization of the scenario that will occur, which will respect both the scheduled plans and the new requirements enforced as well. It is crucial that the Results are absolutely those expected and scheduled because the conditions could change and they could turn out to be no longer suitable for action. A second chance to repeat the plan could take a long time, thereby putting the success of the project at risk. By borrowing the concepts of Increment and "Potential Releasable" from Agile world, each deliverable has to guarantee high quality, well validation, and completeness ${ }^{8}$ of the delivery. This means that each Increment released is usable within the time window available. The result is an approach consisting of micro-goals. Therefore, each (potential) usable deliverable can be considered as selfcontained inside the time-constrained. Thus, even if the activities were stopped by new government regulations, the micro-goal is ready to be delivered and all actors may work on new tasks. The project assumes a stepped behavior under a delivery capability. Almost one Increment has to be contained in each time window. In a pandemic scenario, it is neither easy nor cheap to plan for a medium or long-term period. It is possible to prepare the ground by establishing processes, procedures, and operational templates (usually called "organizational process assets" (Project Management Institute, 2017)) that

${ }^{7}$ https://scrumdictionary.com/term/potentially-releasable-increment/

${ }^{8} \mathrm{https} / / / \mathrm{www}$.mountaingoatsoftware.com/blog/what-does-it-mean-to-be-potentiallyreleasable 
are always valid during a pandemic. Moreover, the additional purpose involves facilitating the operation of the project actors and team, in order to move their habits towards the new delivery perspectives. These assets have to be reviewed with strict cadence to be always aligned with the new requirements enforced. The project managers' knowledge areas to guard are the same as a normal scenario. This includes scope management, risks and planning, etc. However, the "triad" and the time windows involve continuous elicitation of new potential requirements (as government regulations) that have to be scheduled in a plan within a window time, with the use of proper organizational process assets. When identified, the project managers should plan an appropriate Reaction, the correct time for Execution, and the correctness of Results within a time window. It is the project manager's duty to be sure of the correctness of micro-goal during the execution and before its release.

The project managers' mindset, which is the second dimension identified, is a very large and pervasive area of his modus operandi. It generates, de facto, the dynamics of the project during its life. It is typically embodied in the individuals and usually comes from various factors cultivated over the years and from past experiences. It is also shaped by continuous training. For this reason, it is also the deepest in the mind and, consequently, the most challenging in its modification. Managing in a crisis scenario such as a pandemic involves the use of alternative means and modes of communication. An important example of this is the impossibility of direct interaction (face to face) with others. In this case, approaches that favor remote solutions become the common way. As stated by the World Health Organization (2009), it becomes a must to keep the focus on clarity in presentation, on transparency, and on the intent to be pursued, while still selecting the essentiality and precision of the language to be used. If this does not happen, the expected scheduled results would be at risk of project failure. This implies that communication (for example, progress meetings, plans for the allocation of activities to be disclosed or requests for clarification relating to the requirements or the work performed) must be carried out in advance in order to avoid misunderstandings or misinterpretations. Therefore, it is important to consider the following: careful analysis of the language to be used, the effects to be obtained from all the appropriate points of view, and a language that is inevitably enriched by a new medical-health dictionary. Project managers should also additionally follow communication methods that alternate a "vertical" mode (typical of strong hierarchies) and the "horizontal" mode (characterized by servant leadership philosophy (Maurya, 2012)). The choice of the model is due to the need for a reaction time to be very low and the specific results that have a fundamental importance for the future of the project itself. Certainly, these phenomena could seem more natural in a private 
company where the hierarchies are clear and the responsibilities combined with the decision-making possibilities are known. In the case of joined stock companies, the shareholders are the subjects that define the guidelines. The shareholders' meetings can be called within a few hours, and the guidelines can be implemented for the entire crisis period. In the public administration sphere where emergency decisions are taken, these same processes can be applied in a very similar way like joint stock companies. Thus, this is with the addition of "new requirements" involved by bureaucratic aspects. In both contexts, the result must focus on the previously identified "triad" and on an appropriately transmitted communication.

\section{Conclusion}

In conclusion, using a musical similitude, project managers are like orchestra conductors whose "language" is the symphony that the orchestra is playing. Such symphony is the expression that they have chosen to offer to the audience through precise technical and emotional choices, which are also based on the ability of each member of the orchestra. Therefore, an observer witnesses the creation of an entire "discourse" which is dynamically created through a specific language and enriched by the crisis scenario. This is made up of two inseparable dimensions: technical-operative modality and mindset. It is interesting to also observe that the "grammar" is imposed by the medicalsanitary-legislative provisions in force with the specific pandemic crisis scenario. Project managers apply and meet these new requirements throughout the entire project management by using the same knowledge before the crisis, but managing all by the "triad" perspective in all increments. The "discourse" is to be considered closed when the project is officially finished and when all micro-goals have fallen within the preset time windows. Thus, based on the role they have in charge and the consequent overall vision they own, it is necessary that the decision-making and executive responsibility be under the aegis of the project managers. Once all the information gotten from different sources has been obtained and valued, decisions are made independently and with an ethical and professional spirit by following the principle of transparency for their operations.

\section{References:}

1. Axelos. «PRINCE2 - Project Management» [Online]. Available: https://www.axelos.com/best-practice-solutions/prince2.

2. Azwir, A. (2020). «Managing Project in the Middle of Covid-19 Pandemic» [Online]. Available: https://magnaqm.com/projectmanagement-articles/managing-project-in-the-middle-of-covid-19pandemic/. 
3. European Centre for Disease Prevention and Control (2017). Guide to revision of national pandemic influenza preparedness plans.

4. Franklin, M. \& Tuttle, ES. (2008). Focus on Skills Series Suite, The Stationery Office.

5. Greenleaf, R. K. (2002). Servant Leadership: A Journey into the Nature of Legitimate Power and Greatness, Paulist Press; 25 Anvth Edition.

6. International Organization for Standardization (2012). - ISO, ISO 21500 - Guidance on project management, ISO.

7. International Project Management Association (IPMA). «IPMA Standards» [Online]. Available:

https://www.ipma.world/individuals/standard/.

8. KPMG Australia (2020). «COVID-19: The new reality for project and program management,» [Online]. Available: https://home.kpmg/au/en/home/insights/2020/05/coronavirus-covid19-project-program-management-new-reality.html,

9. Lagadec, P. (1993). Preventing Chaos in a Crisis - Strategies for Prevention, Control and Damage Limitation, McGraw Hill Europe.

10. Mallak, L., Kurstedt, H. \& Patzak, G. (1997). «Planning for crises in project management» Project Management Institute.

11. Maurya, A. (2012). Running Lean, Second Edition a cura di, O'Reilly Media Inc.

12. Project Management Institute (2017). A Guide to the Project Management Body of Knowledge (PMBOK® Guide)-Sixth Edition, Pennsylvania: Project Management Institute Inc.

13. Project Management Institute (2017). Project Manager Competency Development Framework - Third Edition, Pennsylvania: Project Management Institute Inc.

14. Schwaber, S. J. (2017). The Scrum Guide TM The Definitive Guide to Scrum: The Rules of the Game.

15. The Agile Manifesto. http://agilemanifesto.org

16. World Health Organization (2009). Pandemic influenza preparedness and response.

17. National Centre for the Prevention and Control of Disease (2020).Ministry of Health, National Plan For Preparedness And Response To An Influenza Pandemic, Italy. 